\title{
VARIATIONS IN NICOTINE YIELDS BETWEEN SINGLE CIGARETTES
}

\author{
Maciej Ł. Goniewicz ${ }^{1,2}$, Bartosz Koszowski ${ }^{1}$, Jan Czogała ${ }^{1}$, Tomasz Kuma ${ }^{1}$, Michał Gawron ${ }^{1}$, Leon Kośmider ${ }^{1}$, \\ Jakub Knysak', Andrzej Sobczak ${ }^{1,3}$ \\ ${ }^{1}$ Department of General and Analytical Chemistry, School of Pharmacy and Laboratory Medicine, Medical University of Silesia, Sosnowiec, \\ Poland \\ ${ }^{2}$ Tobacco Dependence Research Unit, Wolfson Institute on Preventive Medicine, Queen Mary University of London, UK \\ ${ }^{3}$ Institute of Occupational Medicine and Environmental Health, Sosnowiec, Poland
}

\section{SUMMARY}

Introduction and Aims: It is beyond any doubt that nicotine yield in cigarettes as determined using standard ISO method bears almost no relation to smokers' actual intake. However, the ISO method is still in use in many countries where the government is responsible for controlling and monitoring cigarette quality. The aim of the study was to measure the nicotine yield in single cigarettes and to evaluate their statistical distribution among the same brand.

Materials and methods: Nicotine yields were measured according to the ISO method in single cigarettes of the twenty most popular Polish brands of cigarettes.

Results: Relative standard deviation of nicotine yields in single cigarettes of the same brands varied from $16 \%$ to $34 \%$. Relative differences between nicotine yields in a single cigarette of a particular brand and the mean value varied from $-65 \%$ to $+76 \%$.

Discussion and Conclusions: The results indicate high variation in nicotine yields between cigarettes of the same brand. Such variation might affect compensatory smoking. This provides another reason why yields estimated using the standard ISO method are potentially misleading to smokers. Further studies are needed to better understand the implications of within-brand variability in yields for tobacco product regulation.

Key words: nicotine, cigarettes, tobacco smoke, cigarette smokers, ISO, FTC

Address for correspondence: M. Ł. Goniewicz, Tobacco Dependence Research Unit, Wolfson Institute on Preventive Medicine, Queen Mary University of London, 55 Philpot St., London, E1 2JH, UK. E-mail: m.goniewiczm@gmul.ac.uk

\section{INTRODUCTION}

Directive 2001/37/EC of the European Parliament and of the Council of 5 June 2001 on the approximation of the laws, regulations and administrative provisions of the Member States concerning the manufacture, presentation and sale of tobacco products obliges all Member States to establish a policy on tobacco market control. The Directive regulates many aspects of tobacco products' sale, control, advertisement, labeling, and maximum yields of selected constituents etc. In the U.S., the Family Smoking Prevention and Tobacco Control Act (S. 982) grants authority to regulate tobacco products (including nicotine content in cigarettes) to the U.S. Food and Drug Administration.

Nicotine in cigarette smoke shall be measured on the basis of international standard ISO 10315 (1) which is analogous to US FTC method (2). The standard describes a method for determination of nicotine in smoke condensate by means of gas chromatography. Cigarettes are usually smoked in a series of five or twenty, using a standard smoking machine. Smoking conditions are as follows: puff volume $35 \pm 0.25 \mathrm{~mL}$, puff duration $2 \pm 0.05 \mathrm{~s}$, intervals between puffs $60 \pm 0.5 \mathrm{~s}$. Cigarettes are smoked until the butt length is $8 \mathrm{~mm}$ from the filter (for filter cigarettes). The generated particulate matter is collected using standard Cambridge filters.
Then the particulate matter is dissolved in a solvent (propan-2-ol) and the obtained solution is analysed by means of gas chromatography. The results of the chromatographic analysis are finally calculated per one cigarette. The method described allows for determination of nicotine in the particulate phase, while excluding the amount of nicotine in the gas phase. Sampling of cigarettes for laboratory control analysis of nicotine shall be performed in accordance with international standard ISO 8243 (3). Sampling requirements describe precisely the number of sampling points to be randomly sampled (shops, supermarkets, vending machines, etc.) and the number of sale units (packets) to be taken at each sampling point for each laboratory sample. Directive 2001/37/ EC also states that the nicotine yield of cigarette shall not be greater than $1 \mathrm{mg}$ per cigarette. The confidence interval allowed for nicotine is $\pm 20 \%$ (sampling at one point in time).

If the information about nicotine yields is provided by manufacturers on the cigarette pack it will represent the mean value of more than 20 cigarettes. Nicotine yield is the amount of nicotine in tobacco smoke generated from a single cigarette under standard laboratory conditions. Nicotine yield depends on many factors, e.g. nicotine amount in the tobacco, design of cigarette, number of ventilation holes in cigarette, filter design, and the way cigarette is smoked. There are no data on whether the yield of nicotine in 
one-cigarette-smoke is the same as the average value, or whether it can differ significantly from cigarette to cigarette. Therefore, the aim of the study was to examine nicotine yield in single cigarettes of the same brand, and to evaluate statistical distribution and differences of nicotine yields among cigarettes of the same brand.

\section{MATERIALS AND METHODS}

Twenty of the most popular cigarette brands in Poland were subjected to analysis (4). Four types of cigarettes were identified in the study: a) cigarettes of higher nicotine yields (declared 0.8 $\mathrm{mg} /$ cigarette), b) cigarettes of low nicotine yields (declared 0.6 $\mathrm{mg} /$ cigarette), c) cigarettes of very low nicotine yields (declared $0.4 \mathrm{mg} /$ cigarette), and d) mentholated cigarettes (declared 0.6 $\mathrm{mg}$ /cigarette). Cigarettes of the same brand were sampled from the same pack, so they were likely from the same batch. Twenty cigarettes from each brand were analysed, and as a result, nicotine was determined in 400 individual samples. Reference cigarettes of 3R4F type were obtained from the University of Kentucky, USA. Single cigarettes were smoked using a single-channel smoking machine (Technical University of Lodz, Poland) in compliance with standard ISO conditions (1).

Nicotine in tobacco smoke was determined using a method described previously (5). Briefly, nicotine from cigarette smoke was extracted using solid sorbent tube with $0.5 \mathrm{~g}$ Porapak P (80-100 mesh). Then nicotine was eluted with $3 \mathrm{~mL}$ of ethyl acetate and analysed with gas chromatograph Varian CP-3800 with capillary column CP-Sil 8CB $25 \mathrm{~m} \times 0.25 \mathrm{~mm}(1.2 \mu \mathrm{m})$ and FID detector (Varian Corporation, USA). The precision of the method was $9.78 \%$, whereas the accuracy was $70.1 \%$ (based on the analyses of standardized vapours) (5). The limit of detection was $0.06 \mathrm{mg}$ of nicotine per cigarette.

Variations in nicotine yields between cigarettes of the same brand or type were expressed as a relative standard deviation (RSD). Analysis of variance was used to test if cigarettes of the various brands differ from each other in nicotine content. All analyses were performed using Statistica 8.0 (StatSoft, USA). Finally, mean yields of each cigarette brand were compared with values provided by manufacturers on the cigarette packs.

\section{RESULTS}

The nicotine yields in examined cigarettes are presented in Table 1 . RSD of nicotine yields in single cigarettes of the same brands varied from $16 \%$ to $34 \%$ (mean $26 \%$ ). Relative differences between nicotine yields in single cigarettes and the mean value of particular brands varied from $-65 \%$ (Brand C) to $+76 \%$ (Brand R). Analyses of variance showed that there is a significant difference in nicotine yield among the examined cigarette brands $(p<0.05)$. Fourteen of the 20 brands had average nicotine yields lower than was declared on the pack by the manufacturer. Out of 20 analysed cigarette brands, only one exceeded the confidence interval of $20 \%$ (declared vs. determined) required for nicotine according to international standard ISO 8243 (Brand F, 28\%).

Detected nicotine yields of $3 \mathrm{R} 4 \mathrm{~F}$ cigarettes varied less than $1 \%$ in comparison with the value declared by the University of Kentucky. Moreover, the standard deviation of nicotine in refer- ence cigarettes was only $5 \%$ and was statistically lower than the mean value for commercially available cigarettes $(\mathrm{p}<0.05)$.

\section{DISCUSSION}

The detected minimum and maximum values for single cigarettes showed that real nicotine yield might be lower or higher by more than $60 \%$ from the mean determined for a particular brand. These results indicate high variation in nicotine yield between cigarettes of the same brand. Mean relative standard deviation of nicotine yields calculated for single cigarettes amounted to $26 \%$. This number is higher compared to data recently published by Geiss \& Kotzias showing less than $10 \%$ variation of nicotine yields among commercial cigarettes of the same brand (15 replicate measurements for each brand, five cigarettes by replicate) (6). Moreover, it is even higher than the RSD recorded for reference cigarettes. This finding might suggest that Polish cigarettes are less standardized than those from some other countries. Further studies are required to explain how within-brand variability in nicotine yields varies across different countries and how this variability correlates with puff numbers.

Out of 20 analysed cigarette brands available in the Polish market, only one exceeded the confidence interval required for nicotine according to international standard ISO 8243. The results indicate that the values declared on a packet of cigarettes are frequently higher than the results determined in our study. Despite the fact that the present study applied a modified analytical procedure (using sorbent tubes instead of Cambridge filters), the results of method validation as well as reference cigarettes analyses proved that the method is very precise and accurate. Moreover, our method measured the nicotine yield of single cigarette by analysing nicotine in both, the particulate and gas phase of tobacco smoke (5). Detected nicotine levels of 3R4F cigarettes varied less than $1 \%$ in comparison with the value declared by the University of Kentucky. Moreover, standard deviation of nicotine in reference cigarettes was only $5 \%$ and was statistically lower than the mean value for commercially available cigarettes $(\mathrm{p}<0.05)$. These findings suggest that the high variability in nicotine yields between commercial cigarettes was due to actual differences between single cigarettes and not to inadequate measurement method.

Although multi-port smoking machines are recommended by ISO standards, the aim of our study required using a single-port machine. The single-port smoking machine enabled determination of nicotine yields in single cigarette smoke, not an average value from 20 or more cigarettes. These machines are commercially available and standardized with ISO/FTC requirements.

It has been shown that nicotine yield in cigarette smoke as measured with ISO/FTC method has almost no relation to smokers' intake (7). Although one study showed that machine-smoked yields were reasonable predictors of the human smoked yields for a group of smokers, but relationship was neither exact nor linear (8). Another study showed correlation between the mouth exposure to nicotine, as estimated by cigarette filter analysis, and urinary nicotine metabolites (9). It has been known for many years that smokers tend to compensate their smoking behaviour and topography in order to maintain a desired nicotine intake, e.g. they take more puffs per cigarette or inhale smoke deeper (10-12). 
Table 1. Results of nicotine levels in mainstream tobacco smoke from single cigarettes

\begin{tabular}{|c|c|c|c|c|c|}
\hline \multirow{2}{*}{ Cigarette brand } & \multicolumn{3}{|c|}{ Determined nicotine yield [ $\mu \mathrm{g} /$ cigarette] } & \multirow{2}{*}{$S^{c}$} & \multirow{2}{*}{$\begin{array}{c}\text { Declared vs. } \\
\text { determined yields }\end{array}$} \\
\hline & Mean $^{\mathrm{a}}$ & $\operatorname{Min}^{b}$ & $\operatorname{Max}^{b}$ & & \\
\hline \multicolumn{6}{|c|}{ Cigarettes of high nicotine yield (declared $800 \mu \mathrm{g} /$ cigarette) } \\
\hline Brand A & 692 & $382(-45 \%)$ & $1001(+45 \%)$ & $166(24 \%)$ & $-14 \%$ \\
\hline Brand B & 751 & $521(-31 \%)$ & $1130(+50 \%)$ & $203(27 \%)$ & $-6 \%$ \\
\hline Brand C & 772 & $278(-64 \%)$ & $1232(+60 \%)$ & $216(28 \%)$ & $-4 \%$ \\
\hline Brand D & 809 & $505(-38 \%)$ & $1209(+49 \%)$ & $186(23 \%)$ & $+1 \%$ \\
\hline Brand $\mathrm{E}$ & 831 & $496(-40 \%)$ & $1232(+48 \%)$ & $233(28 \%)$ & $+4 \%$ \\
\hline \multicolumn{6}{|c|}{ Cigarettes of low nicotine yield (declared $600 \mu \mathrm{g} / \mathrm{cigarette}$ ) } \\
\hline Brand F & 430 & $193(-55 \%)$ & $688(+60 \%)$ & $133(31 \%)$ & $-28 \%$ \\
\hline Brand G & 531 & $381(-28 \%)$ & $757(+43 \%)$ & $106(20 \%)$ & $-12 \%$ \\
\hline Brand $\mathrm{H}$ & 545 & $253(-54 \%)$ & $841(+54 \%)$ & $147(27 \%)$ & $-9 \%$ \\
\hline Brand I & 589 & $439(-25 \%)$ & $810(+38 \%)$ & $94(16 \%)$ & $-2 \%$ \\
\hline Brand J & 669 & $334(-50 \%)$ & $1009(+51 \%)$ & $201(30 \%)$ & $+12 \%$ \\
\hline \multicolumn{6}{|c|}{ Cigarettes of very low nicotine yield (declared $400 \mu \mathrm{gg} / \mathrm{cigarette}$ ) } \\
\hline Brand K & 326 & $232(-29 \%)$ & $441(+35 \%)$ & $59(18 \%)$ & $-19 \%$ \\
\hline Brand L & 350 & $156(-55 \%)$ & $513(+47 \%)$ & $102(29 \%)$ & $-13 \%$ \\
\hline Brand $\mathrm{M}$ & 377 & $180(-52 \%)$ & $562(+49 \%)$ & $128(34 \%)$ & $-6 \%$ \\
\hline Brand N & 390 & $268(-31 \%)$ & $549(+41 \%)$ & $113(29 \%)$ & $-3 \%$ \\
\hline Brand 0 & 436 & $186(-57 \%)$ & $638(+46 \%)$ & $109(25 \%)$ & $+9 \%$ \\
\hline \multicolumn{6}{|c|}{ Mentholated cigarettes (declared $600 \mu \mathrm{g} /$ cigarette) } \\
\hline Brand P & 540 & $321(-41 \%)$ & $806(+49 \%)$ & $157(29 \%)$ & $-10 \%$ \\
\hline Brand $Q$ & 588 & $286(-51 \%)$ & $841(+43 \%)$ & $147(25 \%)$ & $-2 \%$ \\
\hline Brand $\mathrm{R}$ & 594 & $342(-42 \%)$ & $1045(+76 \%)$ & $178(30 \%)$ & $-1 \%$ \\
\hline Brand S & 624 & $471(-25 \%)$ & $877(+41 \%)$ & $131(21 \%)$ & $+4 \%$ \\
\hline Brand T & 664 & $409(-38 \%)$ & $929(+40 \%)$ & $153(23 \%)$ & $+11 \%$ \\
\hline Reference 3R4F & 734 & $718(-2 \%)$ & $752(+2 \%)$ & $37(5 \%)$ & $+<1 \%$ \\
\hline
\end{tabular}

Note: a Mean nicotine yield was determined for 20 single cigarettes of particular brand; ${ }^{b}$ Relative differences from mean value given in brackets were calculated as:

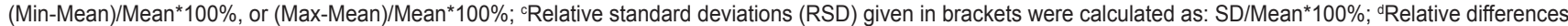
between declared and determined yields were calculated as: (Mean-Declared)/Mean*100\%.

Such compensation occurs when smokers of regular cigarettes switch to low-yield cigarettes, or vice versa (13-15). However, nothing is known about how the variation in nicotine yields within the same brand might affect compensatory smoking. Our data suggest that even within one brand there might be considerable differences in compensation from cigarette to cigarette.

The intake of nicotine varies from person to person, appears to be largely independent of machine-determined yield (16-17). The scientific evidence has exposed the fundamental inadequacy of ISO yields printed on packs. It has been shown that FTC/ISO machine smoking method does not accurately reflect the human smoked cigarettes yields of tar and nicotine across various brands (9). Although these yields give no useful information to smokers about their actual nicotine intake, there is still a need for a standard method that can be used worldwide to investigate and control cigarettes. The ISO standard method is still in use in many countries where governments are responsible for controlling and monitoring cigarettes as consumer products. In the European Union, the Directive 2001/37/EC obliges all Member States to es- tablish a policy on tobacco market control. The Directive regulates many aspects of tobacco products' sale, control, advertisement, labeling, and maximum yields of selected constituents. However, controlling cigarettes for variations in nicotine yield is currently not required. The reason for this might be an assumption that the nicotine yield of every cigarette is similar to the mean estimated for the brand. Our results suggest that if the ISO method is still in force it might require evaluation to control the variation in nicotine yields between single cigarettes.

\section{CONCLUSIONS}

1) There is high variation in nicotine yield between cigarettes of the same brand as measured with standard ISO/FTC method. 2) The real nicotine yield for single cigarettes might be lower or higher by more than $60 \%$ from the mean determined for a particular brand. 3) There might be considerable differences in compensation from cigarette to cigarette within one brand. 4) Fur- 
ther studies are required to explain how within-brand variability in nicotine yields varies across different countries.

\section{Acknowledgement:}

This study was conducted while the first author was at Medical University of Silesia, Poland and was supported by grant KNW-2-035/08.

\section{Conflict of interest statement:}

First author is currently supported by UK Center for Tobacco Control Studies (UKCTCS) and received grant from pharmaceutical company that markets medications to aid smoking cessation.

\section{REFERENCES}

1. ISO 10315: 2000. Cigarettes - Determination of nicotine in smoke condensates - Gas-chromatographic method. 2nd ed. Geneva: International Organization for Standardization; 2000.

2. US Federal Trade Commission. Cigarettes: testing for tar and nicotine content. Federal Register. 1967;32(147):11178.

3. ISO 3308: 1991. Routine analytical cigarette - Smoking machine - Definitions and standard conditions. 3rd ed. Geneva: International Organization for Standardization; 1991.

4. Turek K, Ratajczak J. Tobacco market in Poland. Poradnik handlowca online [Internet]. 2008 [cited 2011 Dec 13];(3):[about 1 p.]. Available from: http://www.poradnikhandlowca.com.pl. (In: Polish.)

5. Koszowski B, Goniewicz ML, Czogala J, Zymelka A, Sobczak A. Simultaneous determination of nicotine and 3-vinylpyridine in single cigarette tobacco smoke and in indoor air using direct extraction to solid phase. Int J Environ Anal Chem. 2009 Jan;89(2):105-17.

6. Geiss O, Kotzias, D. Determination of nicotine in smoke condensate by ion chromatography coupled to ultraviolet detection. Beitr Tabakforsch Int. 2007;22(4):307-11
7. National Cancer Institute. Risks associated with smoking cigarettes with low-machine measured yields of tar and nicotine. Bethesda (USA): National Cancer Institute; 2001.

8. St Charles FK, Kabbani AA, Borgerding MF. Estimating tar and nicotine exposure: human smoking versus machine generated smoke yields. Regul Toxicol Pharmacol. 2010 Feb;56(1):100-10.

9. St Charles FK, Krautter GR, Dixon M, Mariner DC. A comparison of nicotine dose estimates in smokers between filter analysis, salivary cotinine, and urinary excretion of nicotine metabolites. Psychopharmacology (Berl). 2006 Dec;189(3):345-54.

10. Benowitz NL, Hall SM, Herning RI, Jacob P 3rd, Jones RT, Osman AL. Smokers of low-yield cigarettes do not consume less nicotine. N Engl J Med. 1983 Jul 21;309(3):139-42.

11. Byrd GD, Davis RA, Caldwell WS, Robinson JH, deBethizy JD. A further study of FTC yield and nicotine absorption in smokers. Psychopharmacology (Berl). 1998 Oct;139(4):291-9.

12. Byrd GD, Robinson JH, Caldwell WS, deBethizy JD. Comparison of measured and FTC-predicted nicotine uptake in smokers. Psychopharmacology (Berl). 1995 Nov;122(2):95-103.

13. Russell MA, Sutton SR, Iyer R, Feyerabend C, Vesey CJ. Longterm switching to low-tar low-nicotine cigarettes. Br J Addict. 1982 Jun;77(2):145-58

14. Lynch CJ, Benowitz NL. Spontaneous cigarette brand switching: consequences for nicotine and carbon monoxide exposure. Am J Public Health. 1987 Sep;77(9):1191-4.

15. Guyatt AR, Kirkham AJ, Mariner DC, Baldry AG, Cumming G. Longterm effects of switching to cigarettes with lower tar and nicotine yields. Psychopharmacology (Berl). 1989;99(1):80-6.

16. Benowitz NL, Jacob P 3rd. Daily intake of nicotine during cigarette smoking. Clin Pharmacol Ther. 1984 Apr;35(4):499-504.

17. Benowitz NL, Jacob P 3rd, Kozlowski LT, Yu L. Influence of smoking fewer cigarettes on exposure to tar, nicotine, and carbon monoxide. $\mathrm{N}$ Engl J Med. 1986 Nov 20;315(21):1310-3.

Received September 16, 2011 Accepted in revised form December 20, 2011 